\title{
The endocannabinoid system and appetite: relevance for food reward
}

\author{
Gerry Jager* and Renger F. Witkamp \\ Division of Human Nutrition, Wageningen University, Wageningen, The Netherlands
}

\section{Abstract}

Mounting evidence substantiates the central role of the endocannabinoid system (ECS) in the modulation of both homeostatic and hedonic elements of appetite and food intake. Conversely, feeding status and dietary patterns directly influence activity of the ECS. Following a general introduction on the functioning of the ECS, the present review specifically addresses its role in the modulation of hedonic eating. Humans possess strong motivational systems triggered by rewarding aspects of food. Food reward is comprised of two components: one appetitive (orienting towards food); the other consummatory (hedonic evaluation), also referred to as 'wanting' and 'liking', respectively. Endocannabinoid tone seems to influence both the motivation to feed and the hedonic value of foods, probably by modifying palatability. Human physiology underlying hedonic eating is still not fully understood. A better understanding of the role of the ECS in the rewarding value of specific foods or diets could offer new possibilities to optimise the balance between energy and nutrient intake for different target groups. These groups include the obese and overweight, and potentially individuals suffering from malnutrition. Examples for the latter group are patients with disease-related anorexia, as well as the growing population of frail elderly suffering from persistent loss of food enjoyment and appetite resulting in malnutrition and involuntary weight loss. It has become clear that the psychobiology of food hedonics is extremely complex and the clinical failure of $\mathrm{CB}_{1}$ inverse agonists including rimonabant (Accomplia ${ }^{\circledR}$ ) has shown that 'quick wins' in this field are unlikely.

\section{Key words: Endocannabinoid system: Appetite: Food reward value: Eating behaviour}

\section{Introduction}

Humans possess strong motivational systems triggered by the rewarding aspects of food. When palatable foods are abundant, constant restraint to avoid overeating is required. There is mounting evidence for a pivotal role of the endocannabinoid system (ECS) in energy balance and homeostatic and non-homeostatic (hedonic) aspects of food intake ${ }^{(1-6)}$. The ability of the plant Cannabis sativa (and C. indica, in the present paper collectively referred to as Cannabis spp.) and its extracts to stimulate appetite has been documented for many centuries ${ }^{(7,8)}$. Numerous anecdotal accounts from recreational cannabis users complement the evidence for the appetite-stimulating properties of plant cannabinoids (CB). Users report persistent hunger when intoxicated, even when previously satiated, and a specific desire for sweet and high-fat foods, a phenomenon known as the 'munchies'. In research, findings originating from multiple disciplines (medicine, pharmacology, nutrition, sensory science, psychiatry, psychology) illustrate the importance of the
ECS in the control of all aspects of food intake and energy balance ${ }^{(9-12)}$. The last decade prompted a surge of interest in the ECS as a therapeutic target for weight management, the metabolic syndrome, several eating disorders and $\mathrm{CVD}^{(11,13-16)}$. Several pharmaceutical companies have heavily invested in development programmes for selective antagonists/inverse agonists of the $\mathrm{CB}_{1}$ receptor. However, soon after the first drug in this class, rimonabant, reached the European market in 2006 (US Food and Drug Administration had already postponed first approval) this development came to an abrupt halt. Although rimonabant was effective in producing weight loss and improving different cardiovascular risk factors, it was also associated with increased rates of depression, anxiety and suicidal ideation $^{(17)}$. The compound was withdrawn in 2008 and many other companies active in the field announced termination of their research programmes ${ }^{(18)}$. Lately, there has been renewed interest in the modulating role of (endo)cannabinoids in hedonic or reward-driven eating and the potential of the ECS as a therapeutic target in the treatment of overeating and possibly also

\footnotetext{
Abbreviations: AEA, $N$-arachidonoyl ethanolamine (anandamide); 2-AG, 2-arachidonoylglycerol; CB, cannabinoid; $\Delta^{9}$-THC, (-)-trans- $\Delta^{9}$ tetrahydrocannabinol; ECS, endocannabinoid system; GI, gastrointestinal; GPR, G-protein coupled receptor; TR, taste reactivity; TRPV1, transient receptor potential channel type V1.
}

*Corresponding author: Dr Gerry Jager, fax +31 317 483342, email gerry.jager@wur.nl 
'under'-eating. Regarding the latter, the ECS has been linked to unintentional weight loss in elderly individuals $^{(19)}$, and CB are clinically applied in the treatment of disease-related loss of appetite ${ }^{(20,21)}$. In the therapeutic field of weight management and metabolic diseases, this renewed interest is fuelled by recent developments in pharmacology, such as the development of partial/neutral antagonists or peripherally restricted compounds to target the $\operatorname{ECS}^{(22-24)}$. The present review is not intended to fully cover the involvement of the ECS in all aspects of food intake and energy balance. Rather, it expands upon previous reviews by concentrating on the role of the ECS in reward-driven eating and the hedonic aspects of food intake. For its homeostatic role, for example, in controlling metabolic functions such as energy balance and food intake and its actions on peripheral tissues (adipocytes, hepatocytes, gastrointestinal (GI) tract), readers are referred to recent reviews on this topic ${ }^{(9,25,26)}$.

The present review starts with a fundamental perspective on the ECS, introducing the biochemistry of plant-derived and endogenous $\mathrm{CB}$ and their role in peripheral and central metabolic regulation. This is followed by a brief discussion of food reward, its key concepts and neurophysiology. Next, the present knowledge on the role of (endo)cannabinoids in normal appetite control is summarised, with a focus on hedonic eating (eating in the absence of any energetic or nutritional need). Then, switching to a clinical perspective, eating disorders where dysfunction of the ECS might be involved are discussed, along with developments in therapeutic applications of $\mathrm{CB}$ agents in conditions where appetite either needs to be diminished or stimulated. Finally, the present review identifies some key issues in the translational domain, i.e. the validity of animal models with regard to some aspects of human eating behaviour, and important remaining questions that need to be resolved.

The endocannabinoid system: a versatile and evolutionary well-conserved signalling system

\section{Endocannabinoids and phytocannabinoids}

Endocannabinoids are signalling molecules derived from long-chain fatty acids $\left(\geq \mathrm{C}_{18}\right.$ ), playing important roles in a wide variety of biological processes. By definition, the term endocannabinoid is limited to those compounds displaying significant affinity to the $C B$ receptors $C_{1}$ and $\mathrm{CB}_{2}^{(27)}$. These receptors, shown to bind (-)-trans- $\Delta^{9}$-tetrahydrocannabinol $\left(\Delta^{9}\right.$-THC) from the $C$. sativa plant, were discovered in the late $1980 \mathrm{~s}^{(28,29)}$. To date, nine 'true' endocannabinoids have been described, including anandamide ( $N$-arachidonoylethanolamine; AEA), its name originating from 'ananda' meaning 'the bliss' in Sanskrit, and 2-arachidonoylglycerol (2-AG) ${ }^{(30)}$ (Fig. 1).

Together with their receptors and enzymes involved in synthesis and breakdown, endocannabinoids constitute

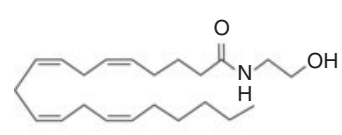

Anandamide

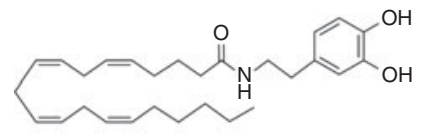

NADA

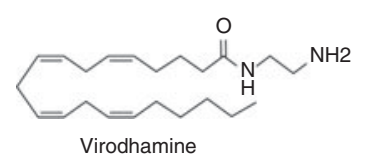

Fig. 1. Chemical structure of some endocannabinoids: anandamide, 2-arachidonoylglycerol, $\mathrm{N}$-arachidonoyldopamine (NADA), noladin ether and virodhamine.

the ECS. The ECS is highly pleiotropic and involved in several processes including energy homeostasis and eating behaviour, reproduction, growth and development, learning and memory, as well as anxiety and immune functions ${ }^{(31-33)}$. The adjective 'cannabinoid' originates from the plant genus Cannabis and predates the discovery of $\mathrm{CB}$ receptors by many years, which can lead to some confusion $^{(34)}$. The term phytocannabinoids (phyto- used here to distinguish them from endocannabinoids) originally refers to a group of terpenophenolic compounds present in Cannabis spp., of which more than 100 have been found so far ${ }^{(35,36)}$. Three examples of these phytocannabinoids are given in Fig. $2(\mathrm{a}-\mathrm{c})$. The earliest reports on the pharmacological effects of Cannabis spp., including the ability to stimulate appetite, date back to several years $\mathrm{BC}^{(37,38)}$. In general, Cannabis refers to C. sativa cultivars, although there is still some discussion whether the genus Cannabis comprises more than one species, i.e. C. sativa and $C$. indica ${ }^{(35,36)}$. Preparations from Cannabis spp. show great variety in absolute and relative phytocannabinoid concentrations, while only a few of these compounds are ligands for $\mathrm{CB}_{1}$ or $\mathrm{CB}_{2}$ receptors. In Cannabis spp., $\mathrm{CB}$ are produced as their carboxylic acid derivatives, known as CB acids, which degrade into their neutral counterparts through the action of heat (smoking, vaporising), sunlight, and storage ${ }^{(39,40)}$. In addition to these 'prototypical' phytocannabinoids, an increasing number of other plant compounds interacting with the ECS are found (see the Dietary compounds with cannabinoid activity section).

\section{The endocannabinoid system as part of an extensive lipid-based signalling network}

More than two decades of research have shown that the ECS is less specific and distinct than originally assumed. Some (if not all) of the 'true' endocannabinoids display 


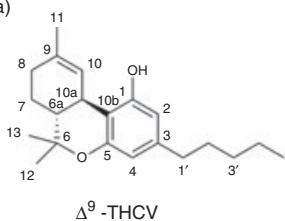

(c)

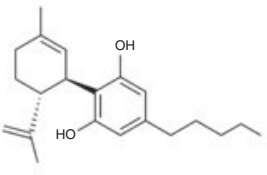

Cannabidiol

(e)

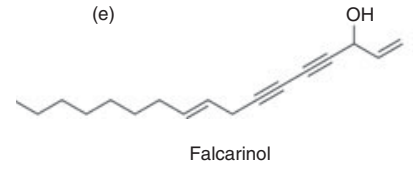

Fig. 2. Examples of some 'phytocannabinoids' from Cannabis and other plants. (a) (-)-Trans- $\Delta^{9}$-tetrahydrocannabinol $\left(\Delta^{9}-\mathrm{THC}\right)$, main psychoactive compound present in Cannabis. (b) $\Delta^{9}$-Tetrahydrocannabivarin $\left(\Delta^{9}-\mathrm{THCV}\right)$; cannabinoid (CB) ${ }_{1}$ antagonist present in Cannabis. (c) Cannabidiol, nonpsychoactive compound from Cannabis with diverse pharmacological spectrum, low affinity for $\mathrm{CB}_{1}$ and $\mathrm{CB}_{2}$ receptors, antagonist for G-protein coupled receptor (GPR) 55, agonist for GPR18 and PPAR- $\gamma$, etc. (d) (E)- $\beta$-caryophyllene, $\mathrm{CB}_{2}$ agonist, widespread in plants. (e) Falcarinol, selective $\mathrm{CB}_{1}$ inverse agonist, covalently binding. Present in different plants, including carrots, celery and Panax ginseng. (f) Yangonin, selective $\mathrm{CB}_{1}$ ligand (over $\mathrm{CB}_{2}$ ) present in Kava (Piper methysticum). See text for further details and references.

'promiscuous' behaviour by activating or blocking other receptors besides $\mathrm{CB}_{1}$ or $\mathrm{CB}_{2}$, with potencies that differ little from those that interact with 'true' $\mathrm{CB}$ receptors $^{(27,34,41)}$. Furthermore, endocannabinoids are now known to be part of a large class of structurally related amides, esters and ethers of fatty acids, which exist in a continuous dynamic equilibrium with each other. The vast majority of these molecules belong to the fatty (acid) amides like AEA, although analogues of 2-AG, including 2-oleoylglycerol and 2-linoleoylglycerol, have also been found. Fatty acid amides (Lipid Maps class FA08; http:// www.lipidmaps.org) are conjugates of different longchain fatty acids and amines including ethanolamine, neurotransmitters (serotonin, dopamine), or simple amino acids. These signalling molecules interact with molecular targets that go far beyond the classical CB receptors, and include a wide range of receptors including $G$-protein-coupled receptor (GPR) 55, GPR18, GPR119, transient receptor potential ankyrin 1 (TRPA1), transient receptor potential channel type V1 (TRPV1), PPAR, as well as several non-receptor targets ${ }^{(27,32,41,42)}$. These receptors and several of their ligands, including fatty acid conjugates with dopamine and glycine, have also been demonstrated in brain tissues of rodents and human subjects, although their relationship with reward circuitry is still unknown ${ }^{(43-45)}$. Pathways for endocannabinoid synthesis $^{(46-48)}$ and their metabolism via hydrolysis ${ }^{(49-52)}$ or oxygenation ${ }^{(42,53)}$ show several crossroads with those of other bioactive lipids. This not only creates several nodes of interaction and regulation, but also results in the formation of 'hybrid' structures, including prostamides and other oxidation products, which are often displaying bioactivity themselves ${ }^{(53-55)}$. Therefore, the ECS is increasingly considered part of a versatile network of lipid mediators that serves to fine-tune homeostasis $(9,56)$. However, in relation to food reward and hedonics, the significance of these 'non-canonical' endocannabinoid receptors and ligands of the ECS remains to be elucidated. Instead, research in this field has thus far entirely focused on the 'prototypical' $\mathrm{CB}_{1}$ receptor. This receptor is presynaptically located at central or peripheral nerve terminals and acts as a modulator of synaptic transmission ${ }^{(57)}$. Its stimulation leads to the inhibition of adenylate cyclase activity, regulation of different $\mathrm{Ca}^{2+}$ and $\mathrm{K}^{+}$channels, and causes the stimulation of mitogen-activated protein kinase. In some cases, $\mathrm{CB}_{1}$ receptors signal through $\mathrm{G}_{\mathrm{s}}$ proteins ${ }^{(27,52)}$. In contrast to the initial view, the distribution of $\mathrm{CB}_{1}$ receptors is not limited to the central nervous system. Their involvement in food intake regulation takes place at different levels, starting from receptors within the GI tract to the regulation of hedonic reward in the brain $^{(14,26,31,58)}$. Their presence in peripheral tissues also provides an explanation for the sustained effects of rimonabant on body weight and the improvement of insulin resistance and blood lipids, in addition to its short-term appetite-decreasing effect. These findings have encouraged the search for so-called 'peripherally restricted' $\mathrm{CB}_{1}$ antagonists with fewer central nervous system side effects, of which several are currently under investigation ${ }^{(10,23,24)}$. In the brain, $\mathrm{CB}_{1}$ is probably the most abundant $\mathrm{GPR}^{(27)}$. Herkenham et al. ${ }^{(59)}$ published a pioneering study on its distribution in the brain in 1990. More recent reviews include those of Freund et al. ${ }^{(60)}$ along with Katona \& Freund ${ }^{(61)}$. Brain $\mathrm{CB}_{1}$ receptors have been linked to both homeostatic and non-homeostatic regulation, with endocannabinoids acting as modulators of orexigenic and anorexigenic neurotransmitters as well as neuropeptides by presynaptic regulation of their release. Anatomically and functionally, the brain ECS shows several connections with other signalling pathways involved in reward, including dopaminergic, opioid and GABA-ergic systems ${ }^{(31,33,43,62-64)}$.

\section{Dietary modulation of endocannabinoid ligands and receptors}

Plasma and tissue concentrations of endocannabinoids and related lipid-derived signalling molecules are influenced by several factors, including food intake, dietary pattern and body weight ${ }^{(31,65)}$. In humans, plasma levels show a circadian rhythm ${ }^{(66)}$. Several studies have found that levels of individual endocannabinoids are higher in the plasma of 
obese compared with lean individuals ${ }^{(65,67,68)}$. Some studies in human subjects report a short-term effect of food intake on endocannabinoid plasma levels. For example, Monteleone et al. ${ }^{(69)}$ showed increased plasma 2-AG levels in a group of eight satiated human subjects who consumed palatable food compared with the consumption of non-palatable food. Remarkably, levels of AEA and other $N$-acyl ethanolamines measured decreased after consuming both types of food. Previous research has shown that circulating $N$-acyl ethanolamines in plasma of women correlated well with total and specific (precursor) plasma levels of NEFA, independently of feeding status ${ }^{(70)}$. The relevance of endocannabinoid plasma levels remains subject to debate as endocannabinoids are released on demand and rapidly metabolised in tissues. Therefore, their plasma levels will probably not directly reflect dynamic changes in discrete areas in the brain and other tissues. Evidence for changes in CB levels in specific brain areas in response to dietary intervention comes from animal studies. For example, fasting increased levels of AEA and 2-AG in the limbic forebrain and to a lesser extent of 2-AG in the hypothalamus of rats. By contrast, hypothalamic $2-\mathrm{AG}$ declined as animals ate $\mathrm{e}^{(71)}$. In mice, short-term fasting showed increased levels of 2-AG (and sometimes AEA) in areas of the brain involved in the regulation of food intake, whereas feeding reduced these levels ${ }^{(72)}$. In diet-induced obese mice, increased levels of AEA and 2-AG were reported in the hippocampus, which has also been linked to the hedonic aspects of eating ${ }^{(73)}$.

Next to these short-term effects (hours), diet can also affect the relative ratios of individual endocannabinoids and their congeners in the longer term (days). Patterns of individual ligands reflect the local availability of their precursor fatty acids in the phospholipid membranes, which are diet related ${ }^{(32,74)}$. For example, studies in rodents and human subjects have shown that increasing the relative proportion of $n$-3 long-chain PUFA in the diet can lead to a decrease in the formation of the 'prototypic' endocannabinoids AEA and 2-AG, which are both derived from the $n-6$ fatty acid arachidonic acid ${ }^{(31,74-76)}$. As the individual congeners possess different receptor affinity (and) or intrinsic activity, these shifts in relative concentrations are likely to have biological implications. However, studies to investigate these mixed ligand effects pose large practical and technical challenges and have not been performed so far. Next to modulation at ligand level, diet has also shown to affect the expression of $\mathrm{CB}_{1}$ receptors in hindbrain and forebrain regions ${ }^{(73)}$. Interestingly, Rojo et al. ${ }^{(77)}$ showed that a high-fat diet given to rats for $4-12$ weeks resulted in an increased functionality of $\mathrm{CB}_{1}$ receptors in the prefrontal cortex, as measured from the stimulation of $\left[{ }^{3} \mathrm{H}\right] \mathrm{GTP} \gamma \mathrm{S}$ binding by a $\mathrm{CB}_{1}$ ligand. This was not seen in animals fed with a high-fat diet for longer periods. Furthermore, $\mathrm{CB}_{1}$ receptor densities as well as endocannabinoid hydrolytic enzymes (monoacylglycerol lipase and fatty acid amide hydrolase) remained unchanged.
The authors suggested that the apparent disturbance in ECS signalling after consuming a high-fat diet may show an adaptation in the longer term.

For studies in human subjects, quantitative imaging of the $\mathrm{CB}_{1}$ receptor using positron emission tomography offers interesting options ${ }^{(78,79)}$. This technology has recently been introduced in $\mathrm{CB}$ research and has been used so far in a small number of applications. In relation to eating behaviour, a study by Gérard et $a l .{ }^{(80)}$ showed that the availability of $\mathrm{CB}_{1}$ was increased in cortical and subcortical brain areas of women with anorexia nervosa in comparison with healthy controls. Although the number of patients ( $n$ 14) was small, and results should be interpreted with care, similar studies provide interesting opportunities for future research.

\section{Dietary compounds with cannabinoid activity}

Remarkably, compounds that can interact with the ECS are also found in plants other than Cannabis spp. For example, fatty acid amides similar to those found in animals are common in plants, in particular in seeds ${ }^{(81-84)}$. However, the amounts consumed, as well as their oral bioavailability, are likely to be low. Therefore, these sources are currently not regarded as relevant for human diets, although local GI effects cannot be excluded. The discovery of AEA in chocolate initially received a great deal of attention ${ }^{(85)}$. The endocannabinoid probably did not originate from the cocoa, and levels were considered not to be of dietary relevance ${ }^{(31)}$. Interestingly, an increasing number of other plant metabolites with affinity for $\mathrm{CB}$ receptors have been discovered in various species. Examples include (E)- $\beta$-caryophyllene (present in many different spices and food plants including oregano, cinnamon and black pepper), falcarinol (found in carrots, parsley and celery) and yangonin (present in Kava; Piper methysticum $)^{(30,82,86,87)}$. Some examples of structures of these other (non-Cannabis) phytocannabinoids are also given in Fig. 2(d-f). Their dietary relevance is still unclear. It is tempting to speculate on the link between food sensation and reward effects from certain herbs and spices and an interaction with $\mathrm{CB}_{1}$ and/or TRPV1 receptors. The TRPV1 receptor, which has the pepper compound capsaicin as one of its most potent currently known agonists, has been proposed as a candidate $\mathrm{CB}_{3}$ receptor ${ }^{(27,34)}$. Next to the covalent $\mathrm{CB}_{1}$ antagonist falcarinol ${ }^{(86)}$, one other potent natural $\mathrm{CB}_{1}$ antagonist is known, the phytocannabinoid $\mathrm{THCV}^{(22,88)}$. This compound has shown interesting properties for weight management and diabetes. Considering the 'promiscuity' of the ECS, it does not seem unlikely that other natural compounds acting on the ECS may be found, including some that are relevant to nutrition. Milk (bovine and human) has been reported to contain significant amounts of the endocannabinoid 2-AG, in addition to $N$-palmitoyl ethanolamine, $N$-stearoyl ethanolamine and $N$-oleoyl ethanolamine, the latter being 
'non-cannabinoid' $N$-acyl ethanolamine ${ }^{(89)}$. Some rodent studies suggest that there is a critical role for the $\mathrm{CB}_{1}$ receptor in the initiation of milk suckling within the first $24 \mathrm{~h}$ of birth ${ }^{(89)}$. More studies are needed to clarify the significance of endocannabinoids in milk or specific milk fractions, either locally within the GI tract or systemically.

\section{Food reward: key concepts and neurophysiology}

This section briefly discusses the concept and measurement of food reward in order to provide some context for references in later sections.

It is common knowledge that highly palatable foods can lead people to eat, even when satiated. Thus, eating can be motivated by hedonics, rather than hunger or homeostatic principles. The rewarding properties of food intake follow a typical cyclical time course with appetitive stages (expectation/anticipation), which sometimes lead to a phase of consummation (hedonic experience/evaluation), followed by a satiety phase ${ }^{(90)}$. These phases have been linked to distinct components of reward, including 'wanting', 'liking' and 'learning' (see Fig. 3). Wanting refers to the motivation to obtain foods or the incentive salience of foods (salience as a 'tag' that makes a food stimulus attractive, attention grabbing, sought after, and 'wanted'). Liking is about the affect or emotion, and in the context of foods about the hedonic evaluation or hedonic impact (pleasure, palatability). The learning phase involves associative conditioning and cognitive processes where wanting and liking for the reward are linked over time. Reward processes are regulated in a network of brain regions, including areas in the lateral hypothalamus, brain stem

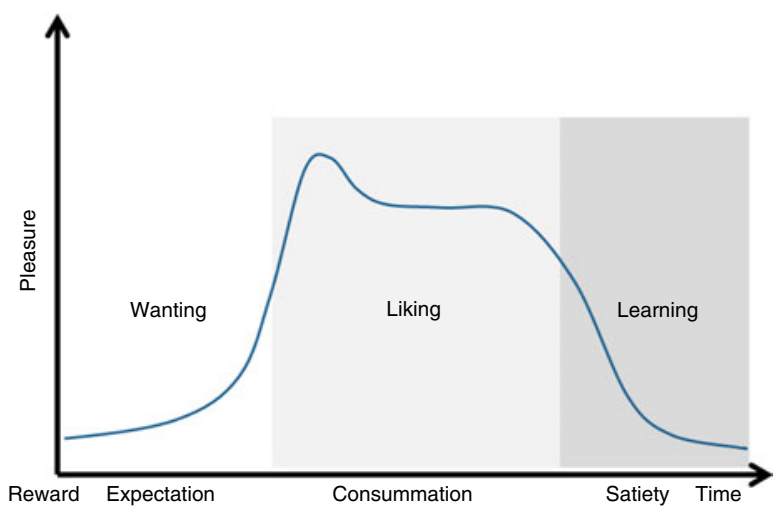

Fig. 3. Food pleasure cycle (redrawn and adapted from Kringelbach et al. ${ }^{(90)}$ ). Food rewards, similar to other fundamental rewards, are associated with a cyclical time course. Typically, rewarding occasions include a phase of anticipation (appetitive stage) or 'wanting' for a reward, which can lead to a phase of consummation (consummatory stage) or 'liking' of the reward, which can have (several) peak levels of pleasure. Depicted here is an increase in appetite during the initial stages of consuming palatable foods, also known as the 'appetiser effect'(153). Finally, a satiety or learning phase occurs, where one learns and updates predictions for the reward. Note that learning can take place throughout the cycle. (A colour version of this figure can be found online at http://www.journals.cambridge.org/nrr). (ventral tegmental area (VTA), parabrachial nucleus $(\mathrm{PBN})$ ), mesolimbic system (amygdala, hippocampus, striatum, nucleus accumbens, ventral pallidum) and (pre)frontal cortex ${ }^{(91-94)}$. Even though wanting and liking often go together, they are not the same and are both necessary for normal reward. At the neuroanatomical level, wanting and liking have been linked to distinctive networks of so-called wanting and liking 'hotspots' in the limbic forebrain (nucleus accumbens, ventral pallidum) and brain stem (VTA, PBN). These hotspots for wanting and liking have (in part) different neurochemistry. Wanting depends on dopaminergic neurotransmission via the medial forebrain bundle. A connected network of hotspots that uses opioid neurotransmission regulates liking and wanting together to enhance food reward, along with other neurochemical signalling systems including endocannabinoids ${ }^{(90-92,95)}$.

Commonly, wanting has been associated with the appetitive stage of food reward, whereas liking is linked to the actual consummation stage. In fact, these terminologies (wanting $v$. liking; appetitive $v$. consummation) are not completely synonymous in terms of conceptual meaning ${ }^{(96,97)}$. However, in the present review, for reasons of comprehensibility, appetitive stages of food reward will be mainly described in terms of food 'wanting', and consummatory stages in terms of food 'liking', and vice versa.

It is important to note that wanting and liking can occur both explicitly and implicitly, that is without conscious awareness. For example, Winkielman et al. ${ }^{(98)}$ showed that subliminally presented happy faces produced no change in self-reported subjective feeling or moods. But it did cause thirsty participants to pour and consume more of a fruit drink afterwards (reflecting wanting). In addition, they also gave higher ratings to the pleasantness and attractiveness of the drink (reflecting liking), with no awareness that they saw the subliminal stimulus. These findings illustrate the need for different procedures to measure explicit wanting and liking on the one hand, and implicit wanting and liking on the other. Several behavioural procedures are available to measure explicit reward components (conscious desire and pleasure), commonly by subjective self-reports and experiments that study goal-directed behaviour $^{(93)}$. Measurement of implicit reward processes such as incentive salience, habits and liking responses requires different methodology compared with assessing explicit reward indices. For desire or wanting, implicit methods may involve operant models; experiments that measure effort or 'willingness to work' to obtain a rewarding stimulus. For implicit measurements of (dis)liking, observational methods such as monitoring oro-facial expressions can be used. The respective paradigms used in animal and human studies to measure implicit and explicit wanting and liking components of food reward will be described in more detail where relevant. 
Endocannabinoids, appetite control and palatability

\section{Food reward and palatability}

Food consumption is rewarding in itself as it replenishes energy and eliminates hunger (an unpleasant sensation); however, everyday experience suggests that humans often eat in the absence of hunger. For Cooper ${ }^{(99)}$, this fits the distinction between 'palatability-dependent appetite and depletion- or deprivation-induced feeding and drinking'. He acknowledges that 'interactions between the two no doubt occur, but we recognize that we may consume food not because we are hungry but because the food is attractive and eating it gives pleasure'. The ECS, with connections to dopaminergic and opioid circuits, appears to be a key player in the modulation of palatability-dependent appetite. It is important to realise that palatability, or pleasantness, is not a fixed function of the sensory properties (taste, aroma, texture, appearance) of a food or beverage. Instead, palatability refers to the hedonic evaluation of the sensory properties and determines food acceptance and preference ${ }^{(100)}$. The common concept is that only a few taste preferences (sweet) or aversions (bitter) are innately present, but most others are developed throughout life ${ }^{(101)}$. Examples are numerous where people develop a liking for flavours initially rejected, such as coffee, beer, bitter-tasting vegetables or spicy foods. Taste intensity and its hedonic evaluation display plasticity as well ${ }^{(102)}$. To illustrate this, many processed foods contain high levels of salt and sugar that compromise health. Although this is acknowledged by the food industry, strategies to reduce sugar and salt content are challenged because consumers have developed a preference for salty and sweet-tasting foods and drinks. Hence, they often rate food items with reduced salt and sugar levels as less palatable. In short, palatability is not a sensory property itself, but refers to the hedonic evaluation of qualitative and quantitative (intensity) sensory characteristics of foods and drinks ${ }^{(100,101)}$. The plasticity of palatability allows modification of palatability-dependent appetite, and is regulated to a substantial degree by the ECS. Still, the underlying mechanisms are far from clear. In the following sections, animal and human studies will be reviewed that illustrate putative central and peripheral mechanisms (neural, biochemical, perceptual and behavioural) of (endo)cannabinoid involvement in food intake and palatability.

\section{Animal studies on the role of (endo)cannabinoids in appetite control and palatability}

It has been well documented that $\mathrm{CB}_{1}$ receptor agonists such as THC, AEA and 2-AG stimulate feeding in animals. In contrast, $\mathrm{CB}$ receptor inverse agonists such as SR141716A (rimonabant) or AM251 suppress feeding (for a review, see Kirkham \& Williams ${ }^{(103)}$ ). Moreover, $\mathrm{CB}_{1^{-}}$ receptor knockout mice are hypophagic and remain leaner overall than wild-type animals ${ }^{(6,104,105)}$. The motivational changes underlying the hyper- and hypophagic effects of the ECS continue to be subject to investigation, but are associated with liking and wanting aspects of reward ${ }^{(91)}$. Stimulation of endocannabinoid activity clearly acts on the appetitive phase of feeding. In these situations, appetitive behaviours are those associated with an animal's tendency to approach foods/drinks, whereas consummatory behaviours refer to the next component, actual ingestion. Appetitive behaviours are also affected by factors other than palatability, such as motivational and emotional factors ${ }^{(91,93,106)}$. With regard to the appetitive phase of feeding, several animal studies have shown that both exogenous and endogenous $\mathrm{CB}_{1}$ agonists reduce the latency to feed in pre-satiated or free-feeding animals ${ }^{(8,107)}$. ECS effects on appetitive behaviours have also been demonstrated using operant models. These involve socalled progressive ratio paradigms in which experimental animals are required to progressively 'work harder' to obtain successive food rewards. $\mathrm{CB}_{1}$ agonists increase the effort an animal is willing to make to obtain food rewards ${ }^{(108-110)}$. In contrast, $\mathrm{CB}_{1}$ inverse agonists (SR141716A, AM4113, AM251) attenuate instrumental responses to rewarding foods and liquids ${ }^{(111-114)}$. There is tentative evidence suggesting that CB-induced modifications in feeding behaviour may be differential with regard to macronutrient content, taste and texture of the ingested foods. For example, Thornton-Jones et al. ${ }^{(115)}$ tested the effects of the $\mathrm{CB}_{1}$ antagonist rimonabant on both motivational state and palatability in rats that consumed a highly palatable fat emulsion (10\% Intralipid) or a $10 \%$ sucrose solution. Via a microstructure analysis of licking behaviour, changes in motivational state and hedonic impact (palatability) could be distinguished. The effects of the $\mathrm{CB}_{1}$ antagonist were compared with the effects of behavioural manipulations: pre-feeding which reduces the motivation to feed, adding quinine (bitter) to the lipid solution, or changing the sucrose concentrations. In general, the effects of rimonabant on the ingestion of the fat solution were greater compared with the sucrose solution, suggesting an interaction between $\mathrm{CB}_{1}$ modulation and macronutrients, taste and texture. In addition, comparisons between the effects observed after drug administration with the diverse behavioural manipulations indicated that the hypophagic effects were mostly explained by changes in the motivation to feed, and not by the changed hedonic impact of the ingesta ${ }^{(115)}$. The latter conclusion, however, has been challenged by other studies that do find support for $\mathrm{CB}$ actions selectively increasing appetitive behaviours and intake of highly palatable foods and solutions, whereas no effect was found with standard isoenergetic chow (compared with highly palatable pellets) or neutral or mildly aversive solutions (water, low-concentration quinine solutions) ${ }^{(108,116,117)}$.

There is growing evidence that $\mathrm{CB}$ affect consummatory components of ingestion (as distinguished from appetitive 
components), such as palatability and orosensory reward. Endocannabinoid stimulation appears to enhance palatability more for rewarding types of foods (sweet and fatty foods) than for bland foods (normal laboratory chow), whereas reducing endocannabinoid tone diminishes perceived palatability (see also Farrimond et $\left.a l^{(107)}\right)$. Earlier works from Koch \& Matthews ${ }^{(118)}$, as well as Williams and colleagues ${ }^{(119,120)}$ investigated the effects of systemic administration of relatively low doses of THC (for example, $0.5,1.0$ and $2.5 \mathrm{mg} / \mathrm{kg}$; intraperitoneally) on food intake in rats receiving different types of rewarding foods. The results showed that stimulation of $\mathrm{CB}$ receptors evoked an increase in intake of more palatable foods compared with normal rat chow in the first $1-4 \mathrm{~h}$ after drug administration. Interestingly, of the different types of palatable chow, those high in only fat increased intake more than chow that was high in both fat and sugar. Still, palatability of sweet (sugar) foods/drinks appears to be affected by CB. For example, Higgs et al. ${ }^{(121)}$ used microstructural analysis of sucrose drinking in rats to examine the effects on palatability of THC, the endocannabinoids AEA and $2-\mathrm{AG}$, and of the $\mathrm{CB}_{1}$ inverse agonist rimonabant. Free-feeding rats (hence, not deprived of foods) were trained to consume a $10 \%$ sucrose solution and their licking behaviour (rate, number of licking bouts, duration per bout, cumulative lick curves across fixed time bins) was closely monitored and compared with reference standards to distinguish between licking patterns seen when manipulations affect orosensory reward variables $v$. satiation. The results were overall supportive for a CBinduced increase in palatability for both exogenous and endogenous agonists, whereas the antagonist seemed to reduce the palatability of the sucrose solution ${ }^{(121)}$. Another direct measure of palatability is the taste reactivity (TR) test developed by Grill \& Norgren ${ }^{(122)}$. The TR test measures palatability of a flavoured solution by monitoring mimetic responses of an animal. The solution is infused directly into the animal's oral cavity via an implanted intra-oral cannula ${ }^{(123)}$. By doing this, the TR test is able to measure consummatory responses in the absence of appetitive behaviour. Palatable solutions, such as sucrose, elicit a characteristic set of hedonic oro-facial responses, involving tongue protrusions and licking of the mouth/lips; whereas aversive solutions, such as quinine, elicit rejection responses, such as gaping, chin rubs and paw threading $^{(122,123)}$. Jarrett et al. ${ }^{(124,125)}$ performed several experiments with rats to test the effects of both $\mathrm{CB}_{1}$ agonists and antagonists on palatability using the TR test. Their findings showed that low doses of THC $(0.5 \mathrm{mg} / \mathrm{kg}$ intraperitoneally) enhanced the palatability of sucrose solutions regardless of their concentration. Therefore, the effect of THC was not differentially affected by the baseline palatability of the infused solution. This effect appears to be mediated by the $\mathrm{CB}_{1}$ receptor, because it was reversed by pre-treatment with rimonabant ${ }^{(125)}$. Intriguingly, further findings from Jarrett et al. ${ }^{(125)}$ suggest that the effect of CB ligands on palatability of foods is not restricted to positive hedonic properties of taste, but also involves modulation of aversive (bitter) tastes. The authors demonstrated that THC could reduce rejection of a highly unpalatable quinine solution, whereas pre-treatment with $\mathrm{CB}_{1}$ antagonists/ inverse agonists increased the rejection of unpalatable tastants ${ }^{(125)}$. There are other reports, however, where amplification of the positive hedonic impact of endocannabinoids such as AEA to intra-oral sucrose is confirmed, but no changes in 'disliking' reactions to bitter quinine were found $^{(126)}$.

As for the neurophysiological mechanisms by which endocannabinoids exert their actions on regulation of food intake and palatability, most of the attention has gone to the central nervous system. In the brain, areas in the nucleus accumbens shell have been identified as an endocannabinoid hotspot for sensory pleasure ${ }^{(91,126-128)}$. Interestingly, there is emerging evidence that taste function can also be modulated at the peripheral level by hormones and other neuromodulatory factors that act on receptors present in the peripheral gustatory system. Sweet-sensitive taste cells in the peripheral taste system not only express sweet taste receptors (T1R2/T1R3) but $\mathrm{CB}\left(\mathrm{CB}_{1}\right)$ and leptin (Ob-Rb) receptors as well. This suggests that sweet taste sensitivity could be altered peripherally by both anorexigenic (for example, leptin) and orexigenic factors (for example, CB) ${ }^{(129)}$. Support for peripheral alteration of sweet taste sensitivity by endocannabinoids comes from a study in rats, which showed that administration of AEA and 2-AG increased gustatory nerve responses and mimetic responses to sweeteners in a concentration-dependent manner without affecting responses to salty, sour, bitter and umami (savoury) compounds ${ }^{(130)}$. To summarise, the ECS modulates food palatability via both central and peripheral pathways in a way that enables sophisticated fine-tuning of palatability.

\section{Studies in human subjects: marijuana 'munchies' v. controlled laboratory studies}

Numerous anecdotal and descriptive accounts indicate that marijuana (mostly THC and possibly other CB present in C. sativa) stimulates ingestive behaviour and enhances the appreciation of food in humans (for example, $\mathrm{Abel}^{(7)}$, $\operatorname{Tart}^{(131)}$ and Haines \& Green $\left.{ }^{(132)}\right)$. This phenomenon is known as the 'munchies' in popular culture. It has also been well established that marijuana induces a craving for sweet or fatty foods ${ }^{(99,126)}$, although findings from controlled laboratory studies in human subjects are limited and less compelling. Reported data are highly variable and clearly depend on methodological conditions, such as social setting (subjects alone or in groups), different dosing schedules and routes of administration resulting in variable plasma drug levels and subjective levels of becoming 'high', as well as on the energy status of the participants (drug administration under fed or fasted conditions) ${ }^{(133)}$. 
Taking these factors into consideration, controlled laboratory studies in human subjects on the effects of marijuana administration can provide overall verification of the anecdotal accounts of marijuana-induced increases in food intake $^{(133-135)}$. In addition, findings from these studies suggest that marijuana specifically increases appetite for sweet foods (for example, cakes and candy bars). This preference for sweet foods appears to depend on sensory properties rather than macronutrient or energy content alone and as such reflects palatability factors ${ }^{(135)}$. Surprisingly, only one study investigated whether the reported taste-enhancing properties of marijuana reflect true shifts in gustatory functions ${ }^{(136)}$. In a double-blind, placebo-controlled study, the effects of acute marijuana administration on taste intensity and hedonic responses for sweet, sour, salty and bitter food stimuli were monitored at baseline, as well as 2, 4 and $6 \mathrm{~h}$ post-dosing. Findings on taste responses were negative, suggesting that self-reported shifts in taste-responsiveness and hedonics could be a consequence of the effects of marijuana intoxication on memory and higher cognitive processes, instead of alterations of sensory systems ${ }^{(136)}$.

Regarding body weight, studies in healthy volunteers and in obese patients suggest that THC-induced increases in body weight do not solely rely on increased energy intake $e^{(133,136,137)}$. An illustrative finding concerns that of body-weight change due to marijuana administration in healthy volunteers. Foltin et al. ${ }^{(135)}$ exposed their volunteers to $3 \mathrm{~d}$ periods of active marijuana administration alternated with $3 \mathrm{~d}$ placebo periods, whilst subjects lived for 2 weeks in a residential laboratory. They observed that body weight increased an average of $3 \mathrm{~kg}$ over a $3 \mathrm{~d}$ marijuana period and subsequently decreased by nearly $3 \mathrm{~kg}$ over a $3 \mathrm{~d}$ placebo period. These rather dramatic changes in body weight could not be accounted for by the changes in energy intake as a function of marijuana and placebo administration. Possible explanations for the extra weight gain/loss include marijuana-induced increased fluid retention, reduced physical activity and increases in sleeping time, and hypothermia resulting in decreased rest metabolism $^{(135)}$. In chronic cannabis users, however, there is little evidence for consistent and maintained weight gain $^{(131)}$. On the contrary, it has recently been reported that the prevalence of obesity is paradoxically much lower in cannabis users as compared with non-users ${ }^{(137)}$. It is not known why acute THC produces hyperphagic effects and weight gain, whereas chronic administration of THC does not result in increased body weight. Explanations proposed include that THC, which is a partial agonist of the $\mathrm{CB}_{1}$ receptor, might functionally act as an antagonist of endocannabinoids such as 2-AG and AEA, resulting in a relative reduction of endogenous ECS tone. Additionally, chronic THC administration may cause down-regulation and desensitisation of $\mathrm{CB}_{1}$ receptors, resulting in adaptive down-regulation of endocannabinoid signalling ${ }^{(137)}$. Taken together, the previous study indicates weight gain following marijuana administration to be a temporary phenomenon, and this constitutes an interesting avenue for further investigations regarding the role of (endo)cannabinoids in food intake control in humans.

\section{Endocannabinoid dysregulation and food intake Eating disorders and obesity}

The relevance of the ECS for the central mechanisms that drive humans to eat and often over-consume is further strengthened by the notion that visceral obesity is associated with hyperactivity of the ECS. Data from both animal and human studies have shown that the development of obesity co-occurs with increased endocannabinoid levels and $\mathrm{CB}_{1}$ receptor expression ${ }^{(65,68)}$. A detailed discussion of this notion is beyond the scope of the present review. For more details, see other review papers on this topic $^{(2,9,138,139)}$.

Reports concerning the involvement of the ECS and eating disorders such as anorexia nervosa, bulimia nervosa or binge eating disorder are still limited. Interestingly, recent publications point out a possible link between alterations in the physiology of endocannabinoids and other central and peripheral appetite modulators like leptin and ghrelin in patients with eating disorders, thus going beyond the homeostatic control of food intake $^{(11,69,140,141)}$. It is becoming more evident that the ECS is deregulated in eating disorders, which is not solely linked to homeostatic control, but also in the rewarding aspects of aberrant (eating) behaviours occurring in anorexia nervosa, bulimia nervosa and binge eating disorder. For example, abnormal eating behaviours like self-starvation (in anorexia nervosa) or binge-eating episodes (in bulimia nervosa and binge eating disorder) seem to become rewarding in themselves and this may be modulated by endocannabinoid deregulation ${ }^{(11,69,139)}$. Although less specific to eating behaviours, lower levels of $\mathrm{CB}_{1}$ receptor mRNA in female eating disorder patients have been associated with wrist cutting as impulsive selfinjurious behaviour, which may have some rewarding or addictive properties ${ }^{(142)}$.

\section{Therapeutic modulation of the endocannabinoid system in} disease-related anorexia and involuntary weight loss

A second line of evidence on the appetitive properties of THC comes from clinical investigations. Certain diseases, for example advanced stages of cancer or AIDS, are accompanied by wasting syndromes (cachexia), anhedonia and loss of appetite. In these situations, the primary interest in the appetitive properties of THC is in its potential to stabilise and increase body weight. Disease-related anorexia often presents a major medical problem and is associated with decreased quality of life, and increased morbidity and mortality. Malnutrition and food anhedonia are also an 
issue in elderly, especially in frail subpopulations suffering from chronic disease or dementia syndromes ${ }^{(143)}$. At present, a number of approved medical applications of $\mathrm{CB}$ agonists including dronabinol (synthetic THC and main compound of the schedule 3 drug Marinol ${ }^{\circledR}$ ) and nabilone (THC analogue and main ingredient of the schedule 2 drug Cesamet ${ }^{\circledR}$ ) are available as appetite stimulants. A number of studies show that $\mathrm{CB}$ are effective in treating loss of appetite and to reverse weight loss in seriously ill patients ${ }^{(20,22,144-148)}$. Yet, they do not discuss how CB improve appetite and food enjoyment, meaning that the underlying behavioural, physiological and psychological mechanisms are still largely unknown. In part, these mechanisms could be similar to those active in the regulation of normal appetite and food reward value, i.e. CB-induced alterations in chemosensory perception, and both appetitive (food wanting) and consummatory (palatability, food liking) components of ingestion. Treatments like chemotherapy are well known for causing temporary disturbances in taste and smell functions ${ }^{(149,150)}$. There is tentative evidence that THC palliates altered chemosensory perception in cancer patients ${ }^{(145)}$. However, appetite may also improve because $\mathrm{CB}$ relieve disease-related discomfort that negatively affects appetite, such as nausea, pain, anxiety and depression ${ }^{(21,147)}$.

\section{Translational issues and future prospects}

\section{Translational issues}

So far, knowledge of the involvement of the ECS in modulating appetite, food intake and food reward is predominantly based on animal work. This can be explained by ethical and legal restrictions connected to pharmacological interventions with $\mathrm{CB}$ compounds and/or invasive techniques in human subjects. One might consider, for example, studying morphological changes or alterations in neurochemistry in the brain areas important for food hedonics. This is obviously one of the questions that can better or only be investigated in animals. In addition, animal studies have the advantage of a distinct level of experimental control necessary to draw causal conclusions and to control for a range of confounding variables. Nonetheless, it is important to keep in mind the complexities of interspecies scaling and differences in pharmacokinetics. Furthermore, although many aspects of human appetite and eating behaviour can be effectively modelled in animals, some clearly cannot (see also $\mathrm{Kim}^{(151)}$ ). This issue has particular relevance when considering hedonic hunger or reward-driven eating. For example, with respect to odours serving as anticipatory cues signalling food reward value, one can argue that studies in rodents can elucidate the basic mechanisms of endocannabinoid involvement in modulation of food cue reactivity. That might be true, but translation to the human situation remains doubtful, if only because in rodents the sense of smell is far better developed and serves many functions related to food detection, localisation and orienting towards foods. These are no longer, or in a rudimentary form, present in humans ${ }^{(152)}$. In addition, concepts like food enjoyment and reward in humans relate to complex cognitive and emotional appraisal processes that simply cannot be mimicked in animal models.

Another reason why scientific evaluation of $\mathrm{CB}$ and medicinal cannabis applications in humans are still in their infancy has to do with what Robson ${ }^{(38)}$ called the "pariah status of cannabis'. This presents profound methodological challenges reflected in the shortcomings in many of the clinical trials and almost all of the experimental studies conducted in human subjects during the last decades. Studies tend to be underpowered, with suboptimal designs, and are restricted to a limited number of CB compounds licensed for use in humans. Often, these compounds have unsatisfactory profiles or contain herbal material of variable composition and irregular bioavailability ${ }^{(38)}$. Since 2005 , when Robson ${ }^{(38)}$ reviewed the clinical research, there has been a temporary expansion in human studies of $\mathrm{CB}$, mainly fuelled by and co-occurring with the rise and fall of the $\mathrm{CB}_{1}$-selective reverse agonist rimonabant. Therefore, some clinical work has been performed in patients with a focus on food intake and weight status, but despite the urgency and topicality, studies in healthy human volunteers addressing the role of the ECS in modulating food reward are virtually non-existent.

\section{Future prospects}

As the present review illustrates, the ECS appears to be closely involved in the physiology underlying 'hedonic' eating, or eating motivated by pleasure and reward. Current knowledge relies heavily on preclinical work. Building on what we have learned from animal work, several domains can be identified where novel information can be gained on the modulation by endocannabinoids of food liking and wanting. For one, enhancing endocannabinoid activity apparently stimulates the intake of especially sweet and high-fat foods and increases the palatability of these tastes ${ }^{(117,124,129,130)}$. The sensory and psychophysical processes underlying these alterations have not yet been adequately characterised in humans. Furthermore, in studying the role of CB in human food reward and appetite control, it is necessary to go beyond measuring effects on food intake. Intake is the end result of a complex and dynamic cycle of responding to signals of hunger and satiety, along with hedonic cues. This requires a microstructure approach on appetite control $^{(121,153,154)}$ that distinguishes between different aspects like latency to eat, eating rate, intake/volume, as well as changes in hunger and satiety ratings during and in between meals.

The focus in research seems to have been on central pathways, on how the ECS modulates brain neurochemistry in the areas important for food hedonics ('hedonic 
hotspots'), as well as its expression in experienced reward and eventually in feeding behaviour ${ }^{(1,91)}$. For translational research in human subjects, modern neuroimaging techniques like positron emission tomography ${ }^{(78,79)}$ and pharmacological $\mathrm{MRI}^{(155)}$ open up promising avenues to investigate the neurophysiological correlates (brain functions) of $\mathrm{CB}$ modulation of food liking and wanting. But apart from central pathways, future research should also focus on conjoint peripheral and metabolic factors involved in endocannabinoid modulation of appetite and food reward. Recent evidence suggests that the stomach and upper intestines produce endocannabinoids that act as neuromodulators in concert with the major gut peptides (for example, ghrelin, cholecystokinin ${ }^{(156,157)}$ ). This implies that endocannabinoids interact with hormones released from the GI tract to communicate with the brain about the current energy status and food reward and palatability simultaneously ${ }^{(69,158,159)}$. One of the underlying mechanisms might involve alterations of cephalic phase responses (CPR). CPR are induced by the sensory properties of food, such as the sight, smell and taste of food, and include a cascade of pre-absorptive physiological responses that prepare the GI tract for the optimal processing of ingested foods ${ }^{(160)}$. CPR involve changes in plasma levels of $\mathrm{NEFA}^{(161)}$ and probably in endocannabinoid levels ${ }^{(70)}$. This potential direct link between palatable food-related sensory cues and (alterations in) circulating NEFA and endocannabinoid plasma levels still has to be established.

\section{Conclusions}

It has become increasingly clear that the ECS is critically involved in modulating food reward. The ECS is a neurochemical signalling system consisting of $\mathrm{CB}$ receptors and their endogenous ligands. Endocannabinoid activity stimulates appetite by increasing palatability and promotes the deposition of energy as fat in adipose tissue. Food reward comprises two components: one appetitive (orienting towards food), the other consummatory (hedonic evaluation of food during consumption), also referred to as 'wanting' and 'liking', respectively. In the present review an overview of current insights was presented on how (endo)cannabinoids moderate food reward, predominantly based on animal work. With regard to 'liking', administration of $\mathrm{CB}$ agonists enhances the hedonic value of foods, probably by amplifying the palatability of foods, especially for sweet and fatty tastes. Cannabinoid antagonists result in a diminished hedonic value of foods, and therefore reduce intake. The modulation of 'wanting' by endocannabinoid activity has been demonstrated by using free field studies or operant models (progressive ratio paradigms in which experimental animals are required to progressively 'work harder' to obtain successive food rewards). In humans, the physiology underlying hedonic eating, or eating motivated by pleasure and reward, is not fully understood, nor is it clear whether the ECS is involved in similar ways as described in animal literature. At present, there are a number of approved medical applications of $\mathrm{CB}$ agonists to stimulate disease-related loss of appetite in wasting syndromes. In addition, clinical experience with the (failed) $\mathrm{CB}_{1}$ reverse agonist rimonabant provided some support for reduction in appetite and intake in humans, but there are many remaining questions regarding the relative importance and subtle regulation by the ECS of normal appetite regulation and food reward in humans. There is a pressing need for translational research on the regulation by endocannabinoids of food reward in humans, and several domains where novel information can and should be gained were identified. The applied potential of increasing our knowledge on how endocannabinoids modulate reward-driven eating in humans will guide improvement of existing or development of new strategies to guide hedonic eating. The ultimate goal might be to either decrease the sensitivity to reward signals connected to 'unhealthy' foods, or to increase the hedonic value of 'healthy' or nutrient-dense foods and diets. This contributes to solving two major problems with huge public health, societal and economic impacts: overeating and obesity on one side of the spectrum, and malnutrition and loss of appetite/food enjoyment in the sick and elderly on the other.

\section{Acknowledgements}

This research received no specific grant from any funding agency in the public, commercial or non-profit sectors. G. J. and R. F. W. conducted a review of the literature and co-drafted the manuscript. Both authors made a critical review of the draft. We thank Claire Aucella for proofreading the manuscript.

There are no conflicts of interest.

\section{References}

1. Kirkham TC (2009) Endocannabinoids and the nonhomeostatic control of appetite. Curr Top Behav Neurosci 1, 231-253

2. Kirkham TC \& Tucci SA (2006) Endocannabinoids in appetite control and the treatment of obesity. CNS Neurol Disord Drug Targets 5, 275-292.

3. Bellocchio L, Cervino C, Pasquali R, et al. (2008) The endocannabinoid system and energy metabolism. $J$ Neuroendocrinol 20, 850-857.

4. Pagotto U, Cervino C, Vicennati V, et al. (2006) How many sites of action for endocannabinoids to control energy metabolism? Int J Obes 30, Suppl. 1, S39-S43.

5. Matias I, Bisogno T \& Di Marzo V (2006) Endogenous cannabinoids in the brain and peripheral tissues: regulation of their levels and control of food intake. Int J Obes 30, Suppl. 1, S7-S12.

6. Cota D, Marsicano G, Tschöp M, et al. (2003) The endogenous cannabinoid system affects energy balance via central orexigenic drive and peripheral lipogenesis. J Clin Invest 112, 423-431. 
7. Abel EL (1971) Effects of marihuana on the solution of anagrams, memory and appetite. Nature 231, 260-261.

8. Kirkham TC \& Williams CM (2001) Endogenous cannabinoids and appetite. Nutr Res Rev 14, 65-86.

9. Silvestri C \& Di Marzo V (2013) The endocannabinoid system in energy homeostasis and the etiopathology of metabolic disorders. Cell Metab 17, 475-490.

10. Pertwee RG (2012) Targeting the endocannabinoid system with cannabinoid receptor agonists: pharmacological strategies and therapeutic possibilities. Philos Trans $R$ Soc B Biol Sci 367, 3353-3363.

11. Marco EM, Romero-Zerbo SY, Viveros MP, et al. (2012) The role of the endocannabinoid system in eating disorders: pharmacological implications. Behav Pharmacol 23, 526-536.

12. Monteleone P (2011) New frontiers in endocrinology of eating disorders. Curr Top Behav Neurosci 6, 189-208.

13. Rosenson RS (2009) Role of the endocannabinoid system in abdominal obesity and the implications for cardiovascular risk. Cardiology 114, 212-225.

14. Cota D (2008) The role of the endocannabinoid system in the regulation of hypothalamic-pituitary-adrenal axis activity. J Neurendocrinol 20, Suppl. 1, 35-38.

15. Woods SC (2007) Role of the endocannabinoid system in regulating cardiovascular and metabolic risk factors. Am J Med 120, Suppl. 1, S19-S25.

16. Woods SC (2007) The endocannabinoid system: mechanisms behind metabolic homeostasis and imbalance. Am J Med 120, Suppl. 1, S9-S17.

17. Christensen R, Kristensen PK, Bartels EM, et al. (2007) Efficacy and safety of the weight-loss drug rimonabant: a meta-analysis of randomised trials. Lancet 370, 1706-1713.

18. Heal DJ, Gosden J \& Smith SL (2009) Regulatory challenges for new drugs to treat obesity and comorbid metabolic disorders. Br J Clin Pharmacol 68, 861-874.

19. Wernette CM, White BD \& Zizza CA (2011) Signaling proteins that influence energy intake may affect unintentional weight loss in elderly persons. J Am Diet Assoc 111, 864-873.

20. Wilner LS \& Arnold RM (2011) Cannabinoids in the treatment of symptoms in cancer and AIDS, 2nd edition \#93. J Palliative Med 14, 509-510.

21. Glare P, Miller J, Nikolova T, et al. (2011) Treating nausea and vomiting in palliative care: a review. Clin Interventions Aging 6, 243-259.

22. Wargent ET, Zaibi MS, Silvestri C, et al. (2013) The cannabinoid $\Delta^{9}$-tetrahydrocannabivarin (THCV) ameliorates insulin sensitivity in two mouse models of obesity. Nutr Diabetes 3, e68.

23. Silvestri C \& Di Marzo V (2012) Second generation CB1 receptor blockers and other inhibitors of peripheral endocannabinoid overactivity and the rationale of their use against metabolic disorders. Expert Opin Invest Drugs 21, 1309-1322.

24. Witkamp RF (2011) Current and future drug targets in weight management. Pharm Res 28, 1792-1818.

25. Bermudez-Silva FJ, Viveros MP, McPartland JM, et al. (2010) The endocannabinoid system, eating behavior and energy homeostasis: the end or a new beginning? Pharmacol Biochem Behav 95, 375-382.

26. Quarta C, Mazza R, Obici S, et al. (2011) Energy balance regulation by endocannabinoids at central and peripheral levels. Trends Mol Med 17, 518-526.

27. Pertwee RG (2010) Receptors and channels targeted by synthetic cannabinoid receptor agonists and antagonists. Curr Med Chem 17, 1360-1381.

28. Matsuda LA, Lolait SJ, Brownstein MJ, et al. (1990) Structure of a cannabinoid receptor and functional expression of the cloned cDNA. Nature 346, 561-564.
29. Munro S, Thomas KL \& Abu-Shaar M (1993) Molecular characterization of a peripheral receptor for cannabinoids. Nature 365, 61-65.

30. Gertsch J, Pertwee RG \& Di Marzo V (2010) Phytocannabinoids beyond the Cannabis plant - do they exist? $\mathrm{Br} J$ Pharmacol 160, 523-529.

31. MacCarrone M, Gasperi V, Catani MV, et al. (2010) The endocannabinoid system and its relevance for nutrition. Annu Rev Nutr 30, 423-440.

32. Di Marzo V, Bisogno T \& De Petrocellis L (2007) Endocannabinoids and related compounds: walking back and forth between plant natural products and animal physiology. Chem Biol 14, 741-756.

33. Di Marzo V \& De Petrocellis L (2012) Why do cannabinoid receptors have more than one endogenous ligand? Philos Trans R Soc B Biol Sci 367, 3216-3228.

34. Pertwee RG, Howlett AC, Abood ME, et al. (2010) International Union of Basic and Clinical Pharmacology. LXXIX. Cannabinoid receptors and their ligands: beyond $\mathrm{CB}_{1}$ and $\mathrm{CB}_{2}$. Pharmacol Rev 62, 588-631.

35. van Bakel H, Stout JM, Cote AG, et al. (2011) The draft genome and transcriptome of Cannabis sativa. Genome Biol 12, R102.

36. Mehmedic Z, Chandra S, Slade D, et al. (2010) Potency trends of $\Delta^{9}$-THC and other cannabinoids in confiscated cannabis preparations from 1993 to 2008. J Forensic Sci 55, 1209-1217.

37. Skaper SD \& Di Marzo V (2012) Endocannabinoids in nervous system health and disease: the big picture in a nutshell. Philos Trans R Soc B Biol Sci 367, 3193-3200.

38. Robson P (2005) Human studies of cannabinoids and medicinal cannabis. Handb Exp Pharmacol 168, $719-756$

39. Verhoeckx KCM, Korthout HAAJ, Van Meeteren-Kreikamp $\mathrm{AP}$, et al. (2006) Unheated Cannabis sativa extracts and its major compound THC-acid have potential immuno-modulating properties not mediated by $\mathrm{CB}_{1}$ and $\mathrm{CB}_{2}$ receptor coupled pathways. Int Immunopharmacol $\mathbf{6}$, 656-665.

40. Eichler M, Spinedi L, Unfer-Grauwiler S, et al. (2012) Heat exposure of Cannabis sativa extracts affects the pharmacokinetic and metabolic profile in healthy male subjects. Planta Medica 78, 686-691.

41. Alexander SPH \& Kendall DA (2007) The complications of promiscuity: endocannabinoid action and metabolism. Br J Pharmacol 152, 602-623.

42. Brown I, Cascio MG, Rotondo D, et al. (2013) Cannabinoids and omega-3/6 endocannabinoids as cell death and anticancer modulators. Prog Lipid Res 52, 80-109.

43. Leishman E, Kokesh KJ \& Bradshaw HB (2013) Lipids and addiction: how sex steroids, prostaglandins, and cannabinoids interact with drugs of abuse. Ann N Y Acad Sci 1282, 25-38.

44. Overton HA, Fyfe MCT \& Reynet C (2008) GPR119, a novel $G$ protein-coupled receptor target for the treatment of type 2 diabetes and obesity. Br J Pharmacol 153, Suppl. 1, S76-S81.

45. Sylantyev S, Jensen TP, Ross RA, et al. (2013) Cannabinoidand lysophosphatidylinositol-sensitive receptor GPR55 boosts neurotransmitter release at central synapses. Proc Natl Acad Sci U S A 110, 5193-5198.

46. Tsuboi K, Ikematsu N, Uyama T, et al. (2013) Biosynthetic pathways of bioactive $N$-acylethanolamines in brain. CNS Neurol Disord Drug Targets 12, 7-16.

47. Wellner N, Diep TA, Janfelt C, et al. (2013) $N$-acylation of phosphatidylethanolamine and its biological functions in mammals. Biochim Biophys Acta 1831, 652-662. 
48. Reisenberg M, Singh PK, Williams G, et al. (2012) The diacylglycerol lipases: structure, regulation and roles in and beyond endocannabinoid signalling. Philos Trans $R$ Soc B Biol Sci 367, 3264-3275.

49. Bisogno T (2008) Endogenous cannabinoids: structure and metabolism. J Neuroendocrinol 20, Suppl. 1, 1-9.

50. Ueda N, Tsuboi K \& Uyama T (2010) Enzymological studies on the biosynthesis of $\mathrm{N}$-acylethanolamines. Biochim Biophys Acta 1801, 1274-1285.

51. Blankman JL, Simon GM \& Cravatt BF (2007) A comprehensive profile of brain enzymes that hydrolyze the endocannabinoid 2-arachidonoylglycerol. Chem Biol 14, $1347-1356$.

52. Fonseca BM, Costa MA, Almada M, et al. (2013) Endogenous cannabinoids revisited: a biochemistry perspective. Prostaglandins Other Lipid Mediat 102-103, 13-30.

53. Rouzer CA \& Marnett LJ (2011) Endocannabinoid oxygenation by cyclooxygenases, lipoxygenases, and cytochromes P450: cross-talk between the eicosanoid and endocannabinoid signaling pathways. Chem Rev 111, 5899-5921.

54. Vandevoorde S \& Lambert DM (2007) The multiple pathways of endocannabinoid metabolism: a zoom out. Chem Biodivers 4, 1858-1881.

55. Yang R, Fredman G, Krishnamoorthy S, et al. (2011) Decoding functional metabolomics with docosahexaenoyl ethanolamide (DHEA) identifies novel bioactive signals. J Biol Chem 286, 31532-31541.

56. DiPatrizio NV \& Piomelli D (2012) The thrifty lipids: endocannabinoids and the neural control of energy conservation. Trends Neurosci 35, 403-411.

57. Cachope R (2012) Functional diversity on synaptic plasticity mediated by endocannabinoids. Philos Trans R Soc B Biol Sci 367, 3242-3253.

58. Cota D, Tschop MH, Horvath TL, et al. (2006) Cannabinoids, opioids and eating behavior: the molecular face of hedonism? Brain Res Rev 51, 85-107.

59. Herkenham M, Lynn AB, Little MD, et al. (1990) Cannabinoid receptor localization in brain. Proc Natl Acad Sci U S A 87, 1932-1936.

60. Freund TF, Katona I \& Piomelli D (2003) Role of endogenous cannabinoids in synaptic signaling. Physiol Rev 83, 1017-1066.

61. Katona I \& Freund TF (2008) Endocannabinoid signaling as a synaptic circuit breaker in neurological disease. Nat Med 14, 923-930.

62. Fattore L, Melis M, Fadda P, et al. (2010) The endocannabinoid system and nondrug rewarding behaviours. Exp Neurol 224, 23-36.

63. Melis M \& Pistis M (2012) Hub and switches: endocannabinoid signalling in midbrain dopamine neurons. Philos Trans R Soc B Biol Sci 367, 3276-3285.

64. Solinas M, Goldberg SR \& Piomelli D (2008) The endocannabinoid system in brain reward processes. BrJ Pharmacol 154, 369-383.

65. Matias I, Gatta-Cherifi B \& Cota D (2012) Obesity and the endocannabinoid system: circulating endocannabinoids and obesity. Curr Obes Rep 1, 229-235.

66. Hanlon EC, Stuhr K, Leproult R, et al. (2013) Circadian rhythm of circulating endocannabinoid, 2-arachidonoylglycerol concentrations following normal and restricted sleep. 23rd Annual Symposium on the Cannabinoids (ICRS), p. 8. http://www.icrs.co/SYMPOSIUM.2013/ICRS2013.PROGRAMME.pdf (accessed May 2014)

67. Matias I, Gatta-Cherifi B, Tabarin A, et al. (2012) Endocannabinoids measurement in human saliva as potential biomarker of obesity. PLOS ONE 7, e42399.
68. Matias I, Gonthier MP, Orlando P, et al. (2006) Regulation, function, and dysregulation of endocannabinoids in models of adipose and $\beta$-pancreatic cells and in obesity and hyperglycemia. $J$ Clin Endocrinol Metab 91, 3171-3180.

69. Monteleone P, Piscitelli F, Scognamiglio P, et al. (2012) Hedonic eating is associated with increased peripheral levels of ghrelin and the endocannabinoid 2-arachidonoyl-glycerol in healthy humans: a pilot study. J Clin Endocrinol Metab 97, E917-E924.

70. Joosten MM, Balvers MGJ, Verhoeckx KCM, et al. (2010) Plasma anandamide and other $N$-acylethanolamines are correlated with their corresponding free fatty acid levels under both fasting and non-fasting conditions in women. Nutr Metab 7, 49.

71. Kirkham TC, Williams CM, Fezza F, et al. (2002) Endocannabinoid levels in rat limbic forebrain and hypothalamus in relation to fasting, feeding and satiation: stimulation of eating by 2-arachidonoyl glycerol. Br J Pharmacol 136, $550-557$.

72. Hanuš L, Avraham Y, Ben-Shushan D, et al. (2003) Shortterm fasting and prolonged semistarvation have opposite effects on 2-AG levels in mouse brain. Brain Res $\mathbf{9 8 3}$ $144-151$.

73. Massa F, Mancini G, Schmidt H, et al. (2010) Alterations in the hippocampal endocannabinoid system in diet-induced obese mice. J Neurosci 30, 6273-6281.

74. Balvers MGJ, Verhoeckx KCM, Bijlsma S, et al. (2012) Fish oil and inflammatory status alter the $n-3$ to $n-6$ balance of the endocannabinoid and oxylipin metabolomes in mouse plasma and tissues. Metabolomics 8, 1130-1147.

75. Hansen HS (2013) Effect of diet on tissue levels of palmitoylethanolamide. CNS Neurol Disord Drug Targets 12, 17-25.

76. Meijerink J, Balvers M \& Witkamp R (2013) $N$-acyl amines of docosahexaenoic acid and other $n-3$ polyunsatured fatty acids - from fishy endocannabinoids to potential leads. Br J Pharmacol 169, 772-783.

77. Rojo ML, Söderström I, Olsson T, et al. (2013) Changes in cannabinoid $\mathrm{CB}_{1}$ receptor functionality in the female rat prefrontal cortex following a high fat diet. Life Sci $\mathbf{9 2}$, $757-762$.

78. Sanabria-Bohórquez SM, Hamill TG, Goffin K, et al. (2010) Kinetic analysis of the cannabinoid-1 receptor PET tracer $\left[{ }^{18} \mathrm{~F}\right] \mathrm{MK}-9470$ in human brain. Eur J Nuc Med Mol Imaging 37, 920-933.

79. Ceccarini J, De Hert M, Van Winkel R, et al. (2013) Increased ventral striatal $\mathrm{CB}_{1}$ receptor binding is related to negative symptoms in drug-free patients with schizophrenia. NeuroImage 79, 304-312.

80. Gérard N, Pieters G, Goffin K, et al. (2011) Brain type 1 cannabinoid receptor availability in patients with anorexia and bulimia nervosa. Biol Psychiatry 70, 777-784.

81. Coulon D, Faure L, Salmon M, et al. (2012) $\mathrm{N}$-acylethanolamines and related compounds: aspects of metabolism and functions. Plant Sci 184, 129-140.

82. Gertsch J (2008) Immunomodulatory lipids in plants: plant fatty acid amides and the human endocannabinoid system. Planta Medica 74, 638-650.

83. Kim S-C, Chapman KD \& Blancaflor EB (2010) Fatty acid amide lipid mediators in plants. Plant Sci 178, 411-419.

84. Chapman KD, Venables BJ, Dian EE, et al. (2003) Identification and quantification of neuroactive $\mathrm{N}$-acylethanolamines in cottonseed processing fractions. JAOCS 80, 223-229.

85. di Tomaso E, Beltramo M \& Piomelli D (1996) Brain cannabinoids in chocolate. Nature 382, 677-678. 
86. Leonti M, Casu L, Raduner S, et al. (2010) Falcarinol is a covalent cannabinoid $\mathrm{CB}_{1}$ receptor antagonist and induces pro-allergic effects in skin. Biochem Pharmacol 79, $1815-1826$.

87. Ligresti A, Villano R, Allarà M, et al. (2012) Kavalactones and the endocannabinoid system: the plant-derived yangonin is a novel $\mathrm{CB}_{1}$ receptor ligand. Pharmacol Res 66, 163-169.

88. Pertwee RG (2008) The diverse $\mathrm{CB}_{1}$ and $\mathrm{CB}_{2}$ receptor pharmacology of three plant cannabinoids: $\Delta^{9}$-tetrahydrocannabinol, cannabidiol and $\Delta^{9}$-tetrahydrocannabivarin. Br J Pharmacol 153, 199-215.

89. Fride E (2008) Multiple roles for the endocannabinoid system during the earliest stages of life: pre- and oostnatal development. J Neuroendocrinol 20, Suppl. 1, 75-81.

90. Kringelbach ML, Stein A \& van Hartevelt TJ (2012) The functional human neuroanatomy of food pleasure cycles. Physiol Behav 106, 307-316.

91. Berridge KC, Ho CY, Richard JM, et al. (2010) The tempted brain eats: pleasure and desire circuits in obesity and eating disorders. Brain Res 1350, 43-64.

92. Berridge KC \& Kringelbach ML (2008) Affective neuroscience of pleasure: reward in humans and animals. Psychopharmacology 199, 457-480.

93. Berridge KC \& Robinson TE (2003) Parsing reward. Trends Neurosci 26, 507-513.

94. Finlayson G, King N \& Blundell JE (2007) Is it possible to dissociate 'liking' and 'wanting' for foods in humans? A novel experimental procedure. Physiol Behav 90, 36-42.

95. Dagher A (2012) Functional brain imaging of appetite. Trends Endocrinol Metab 23, 250-260.

96. Finlayson G, King N \& Blundell JE (2007) Liking vs. wanting food: importance for human appetite control and weight regulation. Neurosci Biobehav Rev 31, 987-1002.

97. Havermans RC (2012) How to tell where 'liking' ends and 'wanting' begins. Appetite 58, 252-255.

98. Winkielman P, Berridge KC \& Wilbarger JL (2005) Unconscious affective reactions to masked happy versus angry faces influence consumption behavior and judgments of value. Pers Soc Psychol Bull 31, 121-135.

99. Cooper SJ (2004) Endocannabinoids and food consumption: comparisons with benzodiazepine and opioid palatability-dependent appetite. Eur J Pharmacol 500, 37-49.

100. Rogers PJ (1990) Why a palatability construct is needed. Appetite 14, 167-170.

101. Lawless H (1985) Sensory development in children: research in taste and olfaction. J Am Diet Assoc 85, $577-582$.

102. Bolhuis DP, Lakemond CM, de Wijk RA, et al. (2010) Effect of salt intensity on ad libitum intake of tomato soup similar in palatability and on salt preference after consumption. Chem Senses 35, 789-799.

103. Kirkham TC \& Williams CM (2004) Endocannabinoid receptor antagonists: potential for obesity treatment. Treat Endocrinol 3, 345-360.

104. Ravinet Trillou C, Delgorge C, Menet C, et al. (2004) $\mathrm{CB}_{1}$ cannabinoid receptor knockout in mice leads to leanness, resistance to diet-induced obesity and enhanced leptin sensitivity. Int J Obes 28, 640-668.

105. Sanchis-Segura C, Cline BH, Marsicano G, et al. (2004) Reduced sensitivity to reward in CB1 knockout mice. Psychopharmacology 176, 223-232.

106. Berridge KC (2009) 'Liking' and 'wanting' food rewards: brain substrates and roles in eating disorders. Physiol Behav 97, 537-550.
107. Farrimond JA, Mercier MS, Whalley BJ, et al. (2011) Cannabis sativa and the endogenous cannabinoid system: therapeutic potential for appetite regulation. Phytother Res 25, 170-188.

108. Guegan T, Cutando L, Ayuso E, et al. (2013) Operant behavior to obtain palatable food modifies neuronal plasticity in the brain reward circuit. Eur Neuropsychopharmacol 23, 146-159.

109. Barbano MF, Castañé A, Martín-García E, et al. (2009) Delta-9-tetrahydrocannabinol enhances food reinforcement in a mouse operant conflict test. Psychopharmacology 205, 475-487.

110. Freedland CS, Poston JS \& Porrino LJ (2000) Effects of SR141716A, a central cannabinoid receptor antagonist, on food-maintained responding. Pharmacol Biochem Behav 67, 265-270.

111. Gallate JE, Saharov T, Mallet PE, et al. (1999) Increased motivation for beer in rats following administration of a cannabinoid $\mathrm{CB}_{1}$ receptor agonist. Eur J Pharmacol 370, $233-240$

112. Thornton-Jones ZD, Vickers SP \& Clifton PG (2005) The cannabinoid $\mathrm{CB}_{1}$ receptor antagonist SR141716A reduces appetitive and consummatory responses for food. Psychopharmacology 179, 452-460.

113. Maccioni P, Pes D, Carai MAM, et al. (2008) Suppression by the cannabinoid $\mathrm{CB}_{1}$ receptor antagonist, rimonabant, of the reinforcing and motivational properties of a chocolateflavoured beverage in rats. Behav Pharmacol 19, 197-209.

114. Salamone JD, McLaughlin PJ, Sink K, et al. (2007) Cannabinoid $\mathrm{CB}_{1}$ receptor inverse agonists and neutral antagonists: effects on food intake, food-reinforced behavior and food aversions. Physiol Behav 91, 383-388.

115. Thornton-Jones ZD, Kennett GA, Vickers SP, et al. (2007) A comparison of the effects of the $\mathrm{CB}_{1}$ receptor antagonist SR141716A, pre-feeding and changed palatability on the microstructure of ingestive behaviour. Psychopharmacology 193, $1-9$.

116. DiPatrizio NV \& Simansky KJ (2008) Activating parabrachial cannabinoid $\mathrm{CB}_{1}$ receptors selectively stimulates feeding of palatable foods in rats. $J$ Neurosci $\mathbf{2 8}, 9702-9709$.

117. Shinohara Y, Inui T, Yamamoto T, et al. (2009) Cannabinoid in the nucleus accumbens enhances the intake of palatable solution. NeuroReport 20, 1382-1385.

118. Koch JE \& Matthews SM (2001) $\Delta^{9}$-Tetrahydrocannabinol stimulates palatable food intake in Lewis rats: effects of peripheral and central administration. Nutr Neurosci $\mathbf{4}$, $179-187$.

119. Williams CM \& Kirkham TC (1999) Anandamide induces overeating: mediation by central cannabinoid (CB1) receptors. Psychopharmacology 143, 315-317.

120. Williams CM, Rogers PJ \& Kirkham TC (1998) Hyperphagia in pre-fed rats following oral $\delta^{9}$-THC. Physiol Behav 65 , $343-346$

121. Higgs S, Williams CM \& Kirkham TC (2003) Cannabinoid influences on palatability: microstructural analysis of sucrose drinking after $\Delta^{9}$-tetrahydrocannabinol, anandamide, 2-arachidonoyl glycerol and SR141716. Psychopharmacology 165, 370-377.

122. Grill HJ \& Norgren R (1978) The taste reactivity test. II. Mimetic responses to gustatory stimuli in chronic thalamic and chronic decerebrate rats. Brain Res 143, 281-297.

123. Berridge KC (2000) Reward learning: reinforcement, incentives, and expectations. Psychol Learn Motiv 40, $223-278$.

124. Jarrett MM, Limebeer CL \& Parker LA (2005) Effect of $\Delta^{9}$-tetrahydrocannabinol on sucrose palatability as measured by the taste reactivity test. Physiol Behav 86, 475-479. 
125. Jarrett MM, Scantlebury J \& Parker LA (2007) Effect of $\Delta^{9}$-tetrahydrocannabinol on quinine palatability and AM251 on sucrose and quinine palatability using the taste reactivity test. Physiol Behav 90, 425-430.

126. Mahler SV, Smith KS \& Berridge KC (2007) Endocannabinoid hedonic hotspot for sensory pleasure: anandamide in nucleus accumbens shell enhances 'liking' of a sweet reward. Neuropsychopharmacology 32, 2267-2278.

127. Berthoud HR (2007) Interactions between the "cognitive" and "metabolic" brain in the control of food intake. Physiol Behav 91, 486-498.

128. Fulton S (2010) Appetite and reward. Front Neuroendocrinol 31, 85-103.

129. Jyotaki M, Shigemura N \& Ninomiya Y (2010) Modulation of sweet taste sensitivity by orexigenic and anorexigenic factors. Endocr J 57, 467-475.

130. Yoshida R, Ohkuri T, Jyotaki M, et al. (2010) Endocannabinoids selectively enhance sweet taste. Proc Natl Acad Sci U $S$ A 107, 935-939.

131. Tart CT (1970) Marijuana intoxication: common experiences. Nature 226, 701-704.

132. Haines L \& Green W (1970) Marijuana use patterns. Br J Addict Alcohol Other Drugs 65, 347-362.

133. Mattes RD, Engelman K, Shaw LM, et al. (1994) Cannabinoids and appetite stimulation. Pharmacol Biochem Behav 49, 187-195.

134. Foltin RW, Brady JV \& Fischman MW (1986) Behavioral analysis of marijuana effects on food intake in humans. Pharmacol Biochem Behav 25, 577-582.

135. Foltin RW, Fischman MW \& Byrne MF (1988) Effects of smoked marijuana on food intake and body weight of humans living in a residential laboratory. Appetite 11, 1-14.

136. Mattes RD, Shaw LM \& Engelman K (1994) Effects of cannabinoids (marijuana) on taste intensity and hedonic ratings and salivary flow of adults. Chem Senses 19, 125-140.

137. Le Foll B, Trigo JM, Sharkey KA, et al. (2013) Cannabis and $\Delta^{9}$-tetrahydrocannabinol (THC) for weight loss? Med Hypotheses 80, 564-567.

138. Matias I \& Di Marzo V (2007) Endocannabinoids and the control of energy balance. Trends Endocrinol Metab 18, $27-37$.

139. Cervino C, Vicennati V, Pasquali R, et al. (2009) Feeding disorders and obesity. Curr Top Behav Neurosci 1, 373-385.

140. Monteleone P, Bifulco M, Di Filippo C, et al. (2009) Association of CNR1 and FAAH endocannabinoid gene polymorphisms with anorexia nervosa and bulimia nervosa: evidence for synergistic effects. Genes Brain Behav 8, 728-732.

141. Monteleone P, Castaldo E \& Maj M (2008) Neuroendocrine dysregulation of food intake in eating disorders. Regul Pept 149, 39-50.

142. Schroeder M, Eberlein C, de Zwaan M, et al. (2012) Lower levels of cannabinoid 1 receptor mRNA in female eating disorder patients: association with wrist cutting as impulsive self-injurious behavior. Psychoneuroendocrinology 37, 2032-2036.

143. Serra-Prat M, Mans E, Palomera E, et al. (2013) Gastrointestinal peptides, gastrointestinal motility, and anorexia of aging in frail elderly persons. Neurogastroenterol Motil 25, $291-\mathrm{e} 245$.

144. Volicer L, Stelly M, Morris J, et al. (1997) Effects of Dronabinol on anorexia and disturbed behavior in patients with Alzheimer's disease. Int J Geriat Psychiatry 12, 913-919.

145. Brisbois TD, de Kock IH, Watanabe SM, et al. (2011) Delta9-tetrahydrocannabinol may palliate altered chemosensory perception in cancer patients: results of a randomized, double-blind, placebo-controlled pilot trial. Ann Oncol 22, 2086-2093.

146. Pertwee RG (2009) Emerging strategies for exploiting cannabinoid receptor agonists as medicines. Br J Pharmacol 156, 397-411.

147. Beal JE, Olson R, Laubenstein L, et al. (1995) Dronabinol as a treatment for anorexia associated with weight loss in patients with AIDS. J Pain Symptom Manage 10, 89-97.

148. Dejesus E, Rodwick BM, Bowers D, et al. (2007) Use of dronabinol improves appetite and reverses weight loss in HIV/ AIDS-infected patients. J Int Assoc Physicians AIDS Care (Chic) 6, 95-100.

149. Gamper EM, Zabernigg A, Wintner LM, et al. (2012) Coming to your senses: detecting taste and smell alterations in chemotherapy patients. a systematic review. J Pain Symptom Manage 44, 880-895.

150. Schiffman SS (2007) Critical illness and changes in sensory perception. Proc Nutr Soc 66, 331-345.

151. Kim SF (2012) Animal models of eating disorders. Neuroscience 211, 2-12.

152. Keller A \& Vosshall LB (2008) Better smelling through genetics: mammalian odor perception. Curr Opin Neurobiol 18, 364-369.

153. Yeomans MR (2000) Rating changes over the course of meals: what do they tell us about motivation to eat? Neurosci Biobehav Rev 24, 249-259.

154. Yeomans MR, Blundell JE \& Leshem M (2004) Palatability: response to nutritional need or need-free stimulation of appetite? Br J Nutr 92, Suppl. 1, S3-S14.

155. Jenkins BG (2012) Pharmacologic magnetic resonance imaging (phMRI): imaging drug action in the brain. NeuroImage 62, 1072-1085.

156. Ameloot K, Janssen P, Scarpellini E, et al. (2010) Endocannabinoid control of gastric sensorimotor function in man. Aliment Pharmacol Ther 31, 1123-1131.

157. Storr MA \& Sharkey KA (2007) The endocannabinoid system and gut-brain signalling. Curr Opin Pharmacol 7, $575-582$.

158. Dickson SL, Egecioglu E, Landgren S, et al. (2011) The role of the central ghrelin system in reward from food and chemical drugs. Mol Cell Endocrinol 340, 80-87.

159. Perelló M \& Zigman JM (2012) The role of ghrelin in reward-based eating. Biol Psychiatry 72, 347-353.

160. Smeets PAM, Erkner A \& De Graaf C (2010) Cephalic phase responses and appetite. Nutr Rev 68, 643-655.

161. Joosten MM, de Graaf C, Rietman A, et al. (2010) Short-term oral exposure to white wine transiently lowers serum free fatty acids. Appetite 55, 124-129. 